\title{
Failure analysis of collector circuits associated with wind farms
}

\author{
Ashley P. Clifton ${ }^{*}$, Amanullah M. Than Oo, and Mohammad T. Arif \\ School of Engineering, Faculty of Science, Engineering and Built Environment, Deakin University, Geelong Waurn Ponds \\ Campus, Geelong, VIC 3220, Australia
}

Received: 15 January 2017 / Received in final form: 7 July 2017 / Accepted: 27 July 2017

\begin{abstract}
Wind farm collector circuits generally comprise several wind turbine generators (WTG's). WTG's are connected in parallel to a substation. This connection acts as the point-of-connection to the national electricity grid. The electrical load in these circuits is close to component (power cables and accessories) ratings. The objective of this paper is to identify cable joint failure paths; and, develop an understanding of specific contributing factors. All findings presented were established from literature review involving data analysis and discussion with industry experts working across the wind industry. Application of forces, inadequate workmanship, incorrect thermal resistance or other contributing factors, all contribute to high conductor operating temperatures. High conductor operating temperatures highlight issues including insufficient environmental heat transfer due to the use of inadequate cable trenching materials. This in turn results in the imbalanced application of force, experienced at the cable joint, as a direct result of frequent thermal expansion and contraction. For most cable joint failures, the root cause is insulation breakdown due to sustained deterioration of the cross-linked polyethylene insulation. This is a direct result from excessive operating temperatures.
\end{abstract}

\section{Introduction}

The operation of high voltage electricity networks has undergone significant change. Rapid increase in operational wind farms has highlighted an increased failure of medium voltage cable joints in cross-linked polyethylene (XLPE) collector circuits. Failed cable joint numbers are at the point of creating a significant financial and technical problem for existing wind farms and new wind farm developments.

\section{Background}

Cable joint failures in wind farms are typically investigated and analysed to identify the cause of failure. This is achieved by conducting a root cause analysis investigation into the failed cable joint. Two root cause analysis investigations are presented here. In case one the investigation was undertaken on a failed cable joint. In case two the investigation was undertaken on a cable joint that until excavation from the ground had been operating as designed. Both investigations were conducted on cable joints from the same Australian wind farm and have been included as background and supporting evidence.

\footnotetext{
* e-mail: aclifto@deakin.edu.au
}

\subsection{Case 1}

The conclusion from this investigation was that the workmanship and quality of the joint preparation and execution was of a high quality. The joint failed at or near the extremity of the slip over joint (SOJ) body. Heating was evident within the joint body, with temperatures

high enough to cause deformation of the XLPE insulation. The root cause of the failure is believed to have been some form of insulation breakdown due to deterioration of the insulation within the cable, due to heating. There appeared to be zero signs of damage from excessive heating to the SOJ boot. This indicated that any heating was from the cable and not the cable joint. There was no clear cause of the heating source, the grub screws were installed correctly and the conductor appeared to be prepared correctly. Evidence from other similar investigations suggests that substantial forces generated from expansion and contraction could stress the connectors used and cause premature failure.

\subsection{Case 2}

The conclusion from this investigation was that the cable joint had been assembled correctly and to a good standard of workmanship. The identified cause of failure was overheating in the joint. During the investigation, it was 


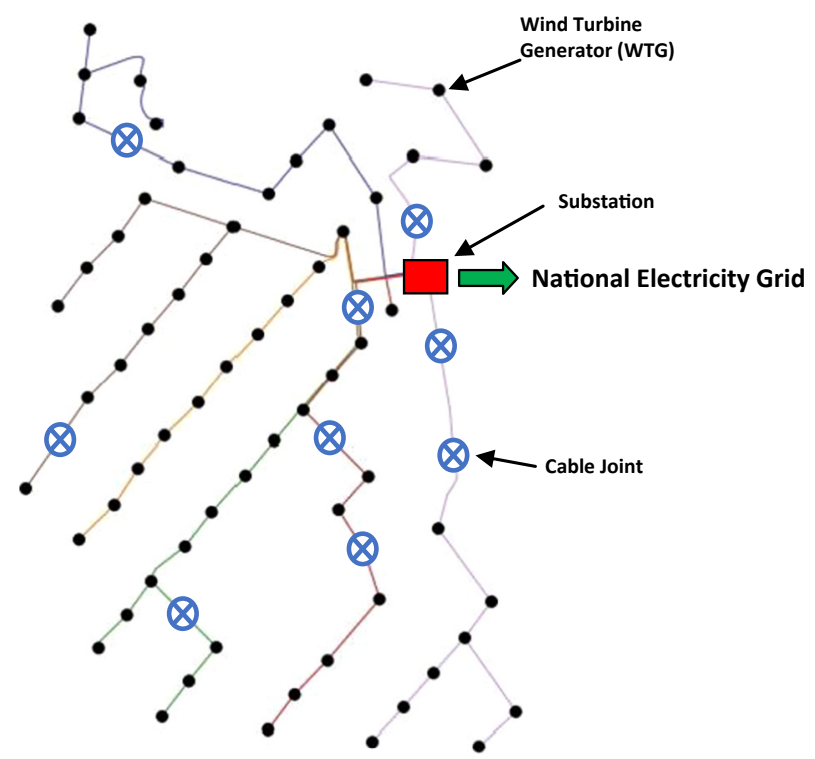

Fig. 1. Typical wind farm collector circuit layout showing cable joints in long cable run.

not possible to examine the electrical contact between the connector body and the cable conductor strands; however, there did not appear to be any issues. It was hypothesized that overheating could be a result of the collector circuit being loaded close to its maximum. Alternatively, the overheating could be due to the use of incorrect bedding materials. This can lead to in-effective environmental heat dissipation.

\section{Literature review}

Wind farms are generally constructed amongst agricultural or rural property. Design requirements specify minimum distances between individual and rows of wind turbine generators (WTG's). This distance typically ranges from $400 \mathrm{~m}$ to $900 \mathrm{~m}$ between WTG's within rows and $500 \mathrm{~m}$ to $1000 \mathrm{~m}$ between WTG rows [1]. The exact distances are dependent upon the type and size of WTG and wind speeds. This in turn influence's the distances between wind farm collector circuits and wind farms point-of-grid connection. Collector groups containing multiple WTG's can be situated at considerable distances from point-of-grid connections. Transport and installation constraints

(cable drum size and weight) impact on maximum cable manufacturing lengths. For $1200 \mathrm{~mm}^{2}$ single-core cable the approximate maximum length is $2000 \mathrm{~m}$. For $500 \mathrm{~mm}^{2}$ three-core cables the approximate maximum length is $1050 \mathrm{~m}$. To facilitate connection of long cable lengths in collector circuits cable joints are a necessary part of the installation process.

Figure 1 shows a typical wind farm collector circuit designed for Australian conditions. This wind farm comprises six collector circuits (as shown by the six colours) all connecting at a central substation. The substation is typically the connection point to the national electricity network. Due to the limitations on cable lengths

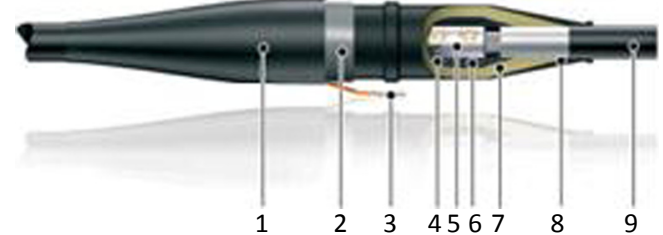

Fig. 2. Cable joint cross-sectional area [2].

mentioned above there is a requirement for installation of cable joints. In Figure 1, cable joints are shown by the blue circle with cross. Cable joints are required at these specific locations to allow connection of the collector circuit to the substation.

To accomplish this design requirement, installation of cable joints in long cable runs is required. The use of overhead transmission lines (commonly used in traditional distribution circuits) is not always viable on wind farms. This is due to the ruggedness of site terrains or potential to greatly impact on existing agricultural practices. For this reason, all wind farm collector circuit cables are installed underground where feasible. A short description on cable joint technology is explained below.

\subsection{Cable joint technology review}

Straight-line cable joints, used as part of wind farm collector circuits typically comprise the following components as shown in Figure 2. The function of nine elements in a cable joint is explained below:

- Outer Jacket (\#1):

- heat-shrink tubes and tape, Cold shrink tubes, RULLE - a flexible tape made of EPDM with an inner sealing layer of butyl rubber, Armouring kit. The main purpose of the outer jacket is protection of the cable joint.

- Joint/cable screen $(\# 2, \# 3)$ :

- metallic material - typically aluminium or copper;

- the main purpose of the joint screen is to secure earth potential all around the joint. The cable screen is connected separately over the joint screen with the main purpose being to keep the joint screen size.

- Contact flanges/connector $(\# 4, \# 5)$ :

- crimp connector, torque-type screw connector, sheartype screw connector, welded connection. The purpose of the connector is to securely join both cable ends;

- the purpose of the contact flanges is to guarantee the connection between the inner conductive layer and the connector.

- Pre-moulded joint body $(\# 6, \# 7, \# 8)$ :

- manufactured in rubber with multiple layers, including an inner conductive layer, insulating layer and outer conductive layer. The purpose of the inner conductive layer is to form a Faradays cage around the conductor. The purpose of the insulating layer is to prevent voltage discharge. The outer conductive layer keeps the electrical field within the insulation of the joint.

- Cable (\#9):

- either single-core or three-core XPLE cable. 


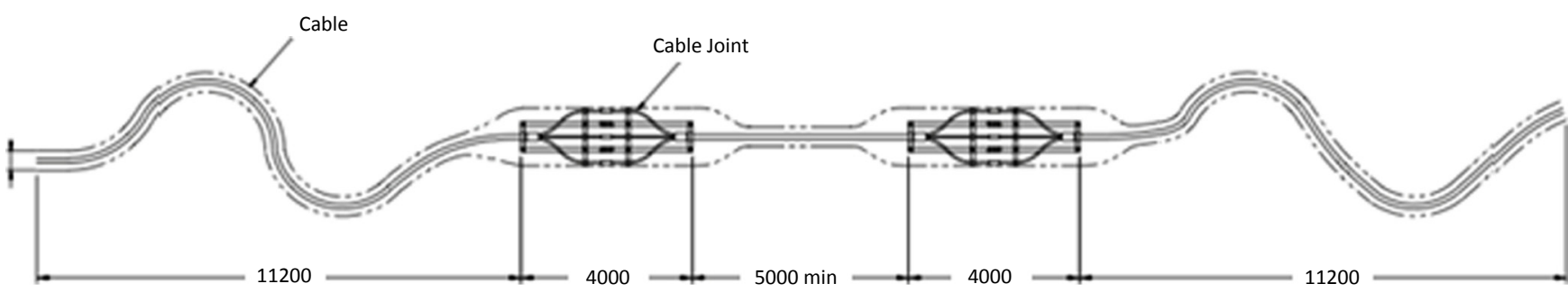

Fig. 3. S-bend cable joint installation.

Welded connections are only suitable for cables that do not contain longitudinal water blocking fibres. Crimp connectors are designed and sized accordingly to fit a specified conductor size. When selecting crimp connectors, it is important to consider conductor stranding (shaped or round). Pre-moulded cable joints are commonly suitable for a range of cable conductor sizes $\left(50-500 \mathrm{~mm}^{2}\right)$ along with a range of cable insulation diameters $(10-46 \mathrm{~mm})$ [2]. Cable joints are typically installed as a loop pit, or S-bend installation or simply with cables butted directly up to one another. Alternatively, but not commonly cable joints can also be installed as above ground terminations. Installation as a loop pit involves the excavation of a large pit in which each end of the cable is looped around before being joined.

Figure 3 shows an S-bend installation. This technique involves both sections of the cable being snaked in an $\mathrm{S}$ pattern prior to installation of the cable joint. This method provides a technique for mitigation of mechanical forces as well as providing excess cable in case of failures.

\subsection{Cable joint failure mechanisms}

\subsubsection{Failure due to application of mechanical force}

There are two extreme possible applications of force experienced by a cable joint as well as everything in between. In the first scenario, there is no conductor expansion (extension) possible because the conductor can neither move longitudinally nor sideward. This is due to the restriction imparted by the trenching backfill materials. In this case, maximum force will be experienced. This scenario is commonplace at wind farms as both ends of cable in collector circuits are solidly terminated above ground. The cable joint is often located somewhere in between. In the second scenario, there is maximum conductor extension possible. This is because the conductor can move freely. In this case the forces in the conductor drop to zero. This situation would not likely occur on a wind farm. An example where this would occur is overhead transmission lines. When heavily loaded the sag in transmission lines is visibly greater compared to times of decreased loading. Conductor extension is related to overall cable length. However, due to the high friction between the conductor and insulation materials, only the last few meters of cable contribute to conductor extension in any real way. It is therefore likely that there exists a maximum cable extension and subsequent force. The length of extension is based on cable cross-sectional area and not overall cable length. In reality the cable is operationally not completely blocked. The cable actually undergoes some slight lateral displacement thus reducing the total force. This displacement would be especially evident at higher temperatures when insulation is weakening [3]. It is clear from work done by Steennis et al. [3,4] that high cycling current loads can have a detrimental effect on cable joints, leading to failure. It is concluded as part of this research that relevant standards may not be fully in accordance with wind farm service conditions. For example, during the IEC heating cycle voltage type tests the test subject can expand freely in the open air. In wind farm service conditions the cable ends are completely blocked by end terminations or installed cable joints.

\subsubsection{Failure due to insufficient thermal dissipation}

Trenching materials with in-adequate thermal resistivity values limit the effective heat dissipation from cables and cable joints. Insufficient thermal dissipation is a very real problem across Australian wind farms. The distances between WTG's means it is commonplace for wind farm sites to cover a range of different environmental installation conditions. Specific site based thermal resistivity values for exact locations where underground cable joints are to be installed need to be used during engineering design processes. Failure to do so presents the risk that componentry is not de-rated accordingly. This can lead to higher than intended load ratings. It is not unusual for thermal resistivity values to only be taken from a selection of test locations across a wind farm site. These test locations may not necessarily be the locations where cable joints are intended to be installed. The use of finite element methods when computing thermal resistances external to cable and cable joints could be utilised to ensure cables and cable joints are effectively rated for specific nonhomogeneous soils and/or backfill types according to installation requirements [5]. Accurate values of thermal resistivity for site based conditions are crucial to ensure correct bedding materials with appropriate vales of thermal resistance are utilised [1].

\subsubsection{Failure due to over loaded collector circuits}

Overloaded collector circuits occur across several Australian wind farms. Overloading is generally an inadvertent by-product of the engineering design process. It occurs when incorrect or generic application and installation data is used as part of collector circuit permissible current rating design calculations and economic optimisation process. It is important to understand appropriate operating limits and ensure collector circuits 
Table 1. Cable joint failure modes, contributing factors and solutions outline.

\begin{tabular}{|c|c|c|}
\hline Failure mode & Contributing factor(s) & Solution(s) \\
\hline \multirow{3}{*}{ Application of mechanical forces } & \multirow{3}{*}{$\begin{array}{l}\text { Contraction and expansion } \\
\text { of metallic materials }\end{array}$} & Trifurcation of cable \\
\hline & & $\begin{array}{l}\text { Excess cable for conductor } \\
\text { expansion and contraction }\end{array}$ \\
\hline & & $\begin{array}{l}\text { Installation of steel frames for } \\
\text { mechanical strength }\end{array}$ \\
\hline $\begin{array}{l}\text { Insufficient thermal } \\
\text { dissipation }\end{array}$ & $\begin{array}{l}\text { Incorrect thermal resistivity } \\
\text { of materials }\end{array}$ & $\begin{array}{l}\text { Utilisation of location based } \\
\text { thermal resistivity data }\end{array}$ \\
\hline \multirow{2}{*}{ Overloaded circuits } & \multirow{2}{*}{$\begin{array}{l}\text { Circuits operating close to } \\
\text { or over the design ratings }\end{array}$} & $\begin{array}{l}\text { Understanding of wind farm } \\
\text { design principles }\end{array}$ \\
\hline & & $\begin{array}{l}\text { Correct application of cable } \\
\text { optimisation techniques }\end{array}$ \\
\hline $\begin{array}{l}\text { Installation and } \\
\text { workmanship quality }\end{array}$ & $\begin{array}{l}\text { Poor workmanship due to } \\
\text { inadequate training } \\
\text { and workplace skills }\end{array}$ & $\begin{array}{l}\text { Adequate and tailored training and } \\
\text { education pathways for wind } \\
\text { farm cable jointers }\end{array}$ \\
\hline $\begin{array}{l}\text { Incorrect technology } \\
\text { application }\end{array}$ & $\begin{array}{l}\text { Incorrect application of } \\
\text { componentry and } \\
\text { technology }\end{array}$ & $\begin{array}{l}\text { Ensure technology and componentry } \\
\text { has been designed, tested and } \\
\text { manufactured specifically for } \\
\text { wind farm applications }\end{array}$ \\
\hline
\end{tabular}

are not designed to operate at or close to theoretical maximums. Whilst economic optimisation is an important design process it should never be allowed to detrimentally impact the technical design process [1].

\subsubsection{Failure due to installation quality}

Cable joint failure can simply be attributed to poor workmanship due to in-adequate training and workplace skills. This results in insulation damage (e.g. nicks in XLPE insulation), incorrect installation techniques (incorrect insulation stripping distances) and introduction of contaminants and moisture. Inadequate workmanship was initially attributed to majority of early cable joint failures across Australian wind farms. Whilst human error is always a possibility there has been substantial efforts in over the last number of years to ensure installation technicians are appropriately trained, educated and experienced.

\subsubsection{Failure due to incorrect technology application and design processes}

Design standards on which product testing is based for XLPE power cables and power cable accessories are not directly relevant to wind farm applications. The repetition of heating cycles $(20$ cycles for cables and 30 cycles for straight joints) $[6,7]$ utilized in the heating cycle type tests represents what is known as cyclic load profiling. The purpose of heating cycle type tests is to ensure power cables and cable joints operate within an acceptable temperature profile for normal operation and fault conditions. Power cable and cable joints that undergo type testing per standards listed above, are not tested for use in Australian wind farms. The duration and repetition of cycles is clearly cyclic and not aligned with wind farm applications. It is not possible to adequately understand and predict the performance of XLPE power cables and cable joints in wind farm applications using existing type testing. Correct application of type testing specific to wind farms applications is required.

\section{Methodology}

The objective of this paper is to identify factors contributing to cable joint failure; and, develop an understanding of failure paths resulting from specific contributing factors. All findings presented were established from literature reviews, data analysis and discussion with industry experts working across the wind industry. These experts included wind farm operations managers, design engineers, developers, consultants and Engineering, Procurement, Construction contractors. The information and data was collated from face-to-face discussion and wind farm design and operating specifications.

Given the commercial nature and sensitivity of this information non-disclosure agreements were implemented. Critical interrogation of data across the spectrum of design, installation, operation and failures was undertaken. This was done to fully understand failure modes and prove contributing factors. Understanding contributing factors and failure modes provided the foundation to explore remediation techniques for existing installations and suggest design implementations for new developments. Remediation techniques are discussed as part of the research findings in the next section.

\section{Findings}

Resolutions to alleviate the application of mechanical forces at cable joint installations include the following. Trifurcation of cables, installation of excess cable to allow for conductor expansion and contraction and installation 
of steel frames to ensure weak points are mechanically strengthened. Trifurcation (only applicable to three-core cables) provides a method that acts to reduce the temperature at the cable joint. This is achieved by separating each cable core a suitable distance away from each other. In this instance the temperature at each point is only due to a single conductor as opposed to contribution form three conductors. It is important to ensure that all required cable layers are re-made around each trifurcated conductor.

Installation of excess cable in both directions, immediately prior to the cable joint provides a scenario whereby cables can contract and expand more freely. This prevents the application of force entirely at the cable joint interface. The use of steel frames to mechanically strengthen cable joints removes the requirement for installation of excess cable. This technique can be installed with single core cable and trifurcated three-core cable. In this scenario, the cable is securely held either side of the cable joint. Again, this is another method to prevent the application of mechanical force entirely at the cable joint interface.

Mitigation of cable joint failure due to insufficient thermal dissipation is achieved via utilisation of sitespecific thermal resistivity data. Use of such data is critical when calculating permissible current ratings as per relevant national and international standards. This approach is equally important when designing wind farm collector circuits to ensure adequate circuit ratings. Correct understanding of wind farm design techniques can ensure that all collector circuits are adequately rated and do not risk potential overload.

Early cable joint failures were quickly attributed to installation quality and workmanship. However, increases in education pathways have seen a rapid decline in this contributing factor. It is still important that adequate training and education pathways for wind farm cable jointers continue to be developed. Pathways need to be tailored to specific wind farm applications and work site conditions.

When selecting componentry for wind farm collector circuits it is important to ensure the required design application aligns with the application intended by original equipment manufacturers (OEM). Power cable and cable joints undergo specific product type testing during the OEM design phase. This occurs prior to manufacture. Type testing ensures power cable and cable joints performance and behaviour is understood during given application conditions. This in turn ensures technology and componentry has been designed, tested and manufactured specifically for wind farm applications. The findings are summarised in Table 1.

\section{Conclusion}

Operating conditions, design assumptions and installation practices contribute to sustained conductor temperature rise outside power cable and cable joint design parameters. The resulting outcome is typically thermal overload leading to insulation failure and voltage discharge. It is evident from the literature review and data analysis that, for most cable joint failures, the root cause is insulation breakdown due to sustained deterioration of the XLPE insulation. This is a direct result from excessive operating temperatures. In several examined failed cable joints there appeared to be minimal signs of damage evident on the SOJ body. This indicates that heating was from the cable and not the joint. Voltage levels during cable joint failure remain within acceptable limits and do not exceed test voltages as detailed in relevant standards. If voltage discharge occurs, it is most likely due to insulation breakdown because of excessive operating temperatures resulting in thermal overload.

\section{References}

1. A. Clifton, Discussion Through Question with Industry Experts in Cable Joint Forum, Melbourne (2015)

2. ABB, Kabeldon Premolded Cable Joints Type SOJ 12-36kV, Product Note (2013)

3. F. Steennis, P. Soepboer, J. Mosterd, P. Buys, P. Oosterlee, L. Bokma et al., Measurement of the force induced by thermal expansion of conductor of MV cables and impact on MV joints, in 21st International Conference on Electricity Distribution, Frankfurt, 10-13 June, 2011

4. F. Steennis, P. Soepboer, J. Mosterd, P. Buys, P. Oosterlee, L. Bokma et al., The thermo mechanical behavior of joints

in MV cable systems exposed to high current loads, in Presented at the JICABLE, 8th International Conference on Insulated Power Cables, Versailles (2011)

5. F.d. Leon, G.J. Anders, Effects of backfilling on cable ampacity analyzed with the finite element method, IEEE Trans. Power Deliv. 23, 537 (2008)

6. IEC, IEC 60502 Part-1: Power Cables with Extruded Insulation and their Accessories for Rated Voltages from $1 \mathrm{kV}(U \mathrm{~m}=1$, $2 \mathrm{kV})$ up to $30 \mathrm{kV}(\mathrm{Um}=36 \mathrm{kV})$ (Standard, 2004)

7. AS/NZS, AS/NZS 1429.1, Electric cables - Polymeric Insulated, Part 1: For Working Voltages 1.9/3.3, (3.6) $k \mathrm{~V}$ up to and including 19/33 (36) kV (Australian/New Zealand Standard $^{\mathrm{TM}}$ Standard, 2006)

Cite this article as: Ashley P. Clifton, Amanullah M. Than Oo, Mohammad T. Arif, Failure analysis of collector circuits associated with wind farms, Renew. Energy Environ. Sustain. 2, 41 (2017) 